He delivered the ball, but, finding his arm powerless, he walked to hospital, and was found, on examination there, to have suffered a comminuted fracture of the humerus, which separated the condyles, and extended into the joint. The forearm could be moved in any direction, and there was no material disfigurement or tumefaction. Reduction was easily effected; and, the parts having been put up in a hinge splint at an angle of forty-eight degrees, he made a good recovery. Anchylosis, however, took place, and he had to be indulged for several successive months as a clerk, \&c., before he could undertake any other military duty.

CASE 4. - J. G-, aged twenty-seven, of temperate habits, who suffered a good deal from syphilitic rheumatism in England, and was greatly debilitated by fever in India, came under my notice in the hills under the following circumstances. While assisting, in obedience to orders to that effect, to take a prisoner to the guard-room, the latter (who was at the time the worse for liquor) seized him by the arm and endeavoured to shake him off and effect his own escape. In this he was but too successful, for, under the pressure thus applied, poor J. G_'s arm snapped asunder like the shank of a clay pipe-as he himself not inappropriately described it,-and fell powerless by his side. The fracture was put up in the usual way, and united firmly within six weeks. He was subsequently invalided for anæmia and lost sight of ; and I fear he will ever retain the impress of his old ailment-syphilis, -and with it a liability to casualties of the kind here contemplated.

CASE 5. - No. 764 Private J. C-, 26th Regiment, aged twenty-five, had a chancre for the first time in 1866 and seven or eight times subsequently ; in fact, "affliction" may fairly be said "to be wedded to his parts," and he bears the brand of syphilis indelibly on his brow. When seen by me, he was thin, sickly.looking, and covered over the trunk with coppery blotches; he spoke harshly through the nose, and the throat was everywhere inflamed and ulcerated. He gave me the following account of his accident. While in the plains, and very much debilitated by fever and diarrhœea, he noticed a swelling-I could not determine whether it was a node or an exostosis-on the right humerus, about its middle or rather lower down, within two and a half or three inches of the joint, which was very painful and tender, and caused him a good deal of distress. Having been subsequently sent to the hills for benefit of change, and being very irritable and despondent at the time, he lost his temper with a beggar who importuned him for alms at Umballa, and to drive him away he "shied" -to use his own words-a piece of bread at him; in doing so the arm gave way in the place already indicated, and the limb fell helpless and deformed by his side. The fracture was put up in camp, and united fairly in six weeks or thereabouts, but the arm remained weak and incapable of much effort, and there was a considerable amount of thickening and enlargement near the seat of the original injury. He died of ulcerative syphilis and exhaustion before I left Kussowlee, and the following analysis-which was most kindly performed for me by Professor Cameron, the distinguished chemist and sanitarian of Dublin-will show that we must look elsewhere than to chemistry for an explanation of the cause of this complication. "A hundred parts" of the bone in question " contain-

\begin{tabular}{|c|c|c|c|c|c|}
\hline Water & & & & & 10.04 \\
\hline Gelatine, fat, vessels, & \&c. & $\ldots$ & $\ldots$ & $\ldots$ & $51 \cdot 14$ \\
\hline Tricalcic phosphate & $\ldots$ & $\ldots$ & ... & $\ldots$ & $35 \cdot 47$ \\
\hline Magnesic phosphate & $\ldots$ & $\ldots$ & $\ldots$ & ... & $1 \cdot 03$ \\
\hline Calcic carbonate & $\ldots$ & $\ldots$ & $\ldots$ & $\ldots$ & $1 \cdot 28$ \\
\hline Alkaline salts, chiefly & y sodic & chloride & & $\ldots$ & $1 \cdot 04$ \\
\hline
\end{tabular}

Dr. Cameron adds: "The above figures show that there is nothing peculiar in the chemical composition of the bone; therefore its brittleness must be due to a physical cause. The portion of the bone adjacent to the united fracture is remarkably light, and presents quite a honeycombed appearance, resembling bones in certain syphilitic affections; other portions of the bone are normal in appearance, and of the ordinary density."

In a subsequent communication with which this gentleman has favoured me, he says: "Curious to say, the sound portion of the bone does not, as far as the relative amount of organic and mineral matter is concerned, differ very sensibly from the dis eused part. Here is the analysis of the former :-

$$
\begin{array}{lcccc}
\text { "Water... } \ldots & \ldots & \ldots & \ldots & 10 \cdot 13 \\
\text { Combustible matter... } & \ldots & \ldots & 50.06 \\
\text { Mineral matter } & \ldots & \ldots & \ldots & 39.81 \\
& & & & \\
& & & 100.00 "
\end{array}
$$

And Professor Smith, whose authority on such a question will not be disputed, kindly informs me that the bone here referred to "affords a well-marked example of venereal caries." He adds that he has seen "numerous instances of spontaneous fractures from fragilitas, internal necrosis, scurvy, and rickets"; and that "all united as soon as in healthy bone."

(To be concluded.)

\section{A CASE OF EPILEPTIC CONVULSIONS DURING LABOUR.}

BY MATTHEW BLOXAM, M.R.C.S., L.S.A., \&c.

ANx variation from the usual phenomena of parturition is so full of interest to the obstetrician that perhaps the following case may be considered so much so as to be worthy of record.

E. S_- aged nineteen, of fair complexion. Said never to have had a day's illness till the present moment, being pregnant for the first time. She was taken in labour on Friday evening, March 7th, 1873.

When examined about nine o'clock, the skin all over the body was peculiarly harsh and dry, though quite free from heat or fever; pulse regular ; tongue clean ; no head symptoms ; urine had just been passed; pains regular; and a peculiar very deep-coloured rusty-brown-black ring around each nipple.

On examination per vaginam, the head was well down in the pelvis (which seemed to be rather over than under the usual standard), and covered by the uterus. The os uteri would not admit the finger during a pain, but in the interval it relaxed to about the extent of a sixpence. The membranes had given way, liquor amnii escaping freely. Head presenting in first position. At the vaginal orifice could be felt what was at first thought to be a thick fold of vaginal mucous membrane, with which it was continuous, as it then seemed, on the right side, but free on the left, and attached above to the symphysis pubis beneath the urethra, and below lost on the posterior wall of the vagina. It was subsequently found that this thick band was attached only by each end-at the upper part just below the urethra, and below to the posterior wall of the vagina, and rather to the right of the median line.

On Saturday, March 8th, I was called in haste at 7 A.M. Was told the patient had just recovered from an hysterical attack. She was making great complaint of the severity of the pains, being quite conscious, and was with great difficulty induced to keep anything like quiet, or remain in bed. On examination the head was well down in the cavity of the pelvis, and labour going on rapidly. In a few moments the patient was attacked with a very severe fit of epilepsy in which she became very livid, and seemed about to die from suffocation. Cold water was freely applied, and the patient soon recovered, becoming perfectly conscious, and at the same time so very unmanageable that she was obliged to be held by myself and attendants to keep her in bed. The convulsions being repeated, it became evident the sooner she was delivered the better; and it being quite impossible to effect this unassisted, owing to the violent struggles of the patient, I asked my brother, Dr. Bloxam, of Mount-street, to oblige me with his advice and assistance. He, having examined the case, thought that it would be better not to give chloroform if it could be avoided, and having carefully made out the attachments of the band before mentioned, determined to remove it, as it not only prevented the descent of the child's head, but so narrowed the vagina that to introduce the forceps was impossible, and even if that could be effected, to extract the head without laceration of the soft parts was out of the question. While the attendants and myself held the patient down on the bed in the necessary position, my brother applied a 
carbolised catgut ligature to the upper end of the band, just below the urethra, and to the lower, well within the vagina, and cut out the intervening portion. The patient was no sooner replaced in bed than she bad another very severe convulsion, and as soon as it had passed off, and while in a state of stupor, Dr. Bloxam rapidly applied the forceps, while the patient was kept from any unexpected movement by myself and the attendants, and she was delivered of a live female infant. The placenta followed in due course, without the least hæmorrhage.

The convulsions continued frequently after delivery, the patient now being quite unconscious during the intervals, with a very rapid pulse, hot skin, and congested face. Cold was applied to the head, and twenty grains of hydrate of chloral given for a dose, to be repeated in two hours if the convulsions again took place. This still being the case up till five o'clock in the afternoon, a powder of eight grains of calomel and two drops of croton oil was given; and fifteen grains of chloral with twenty grains of bromide of potassium in a tablespoonful of water every hour till the fits no longer occurred. When seen again, about nine in the evening, the powder had not operated. The patient quite unconscious; pulse too rapid to count, but firm and full; convulsions rather less frequent. Bromide mixture to be continued. At eleven another convulsion took place, during which a small clot had been passed from the uterus. An enema of castor-oil and turpentine was now given, and the patient left for the night. To continue the bromide mixture.

March 9th, 10 A.M. - No convulsion since 11 o'clock the previous night. Enema operated well, the bowels also being moved several times during the day. Patient in an insensible state, but with great difficulty could be made to put out the tongue. Pulse too rapid to count.

From this time the patient continued slowly to improve; the pulse, however, remained at 130 up till Friday, March 15th, when it fell to 96 per minute, at which rate it still remains. The wounds in the vagina have nearly healed. No convulsions.

In conclusion, let me draw attention to the treatment of this case. First, chloroform was not given on account of the congested state induced by the severity of the epileptic attacks. Secondly, bearing in mind the late Dr. Tanner's views of these attacks during labour, opium was equally to be avoided, none having been given from first to last; and though he says that bromide of potassium is the only drug that can do good in the way of medicine, it seems to me the hydrate of chloral is a valuable remedy under such circumstances, and particularly if combined with the bromide. Thirdly, the diet consisted of large quantities of milk, yelks of eggs, beef-tea, jeliy, \&c., no wine or spirit having been given.

The sudden termination of the convulsions on the expulsion of the small clot from the uterus must not be forgotten, nor the fact that, though the catheter was duly passed during the first few days, but very little urine was ever found in the bladder. The urine was passed into the bed, and the quantity in the course of a day or two became very large; it now. being passed in the usual manner.

The patient was the victim of seduction, and had undergone great mental anxiety. The infant has been brought up by hand from its birth, and with her mother continues to improve daily. From Friday evening till Saturday night the patient had in all twenty fits of epilepsy.

Duke-street, Grosvenor-square, $w$.

\section{EFFECT OF CARBOLIC ACID ON THE URINE.}

BY W. A. PATCHETT,

SENIOR RESIDENT MEDICAI OUHICER, WORKHOUSH HOSPITAL, MANCHESTER.

$\mathrm{I}_{\mathrm{N}}$ The Lancet of April 12th, a letter appeared by Mr. James Nicholls, F.R.C.S., calling attention to a peculiar discolouration of the urine which he had observed after the external use of carbolic acid to a raw surface, and asking whether others had observed the same phenomenon, and if it was a constant sequel to the external application of the acid, and what was its probable cause?

During the past eight or twelve months I have myself repeatedly noticed that carbolic acid lotion (of the strength of 1 to 40) applied externally to a raw surface has, in from four to forty-eight hours, produced a blackish or dark olivegreen discolouration of the urine. The urine looks exactly like an infusion of mint or the colour produced by the addition of a little iron to a vegetable infusion, as of tea or digitalis. This discolouration does not occur with any regularity or constancy. Contrary to the experience of Mr. Nicholls, I have of ten seen the urine discoloured by the internal use of carbolic acid; but unless given in poisonous doses the colour is not so deep as that produced by the external application of the acid. The discolouration appears to occur in healthy individuals only when the acid is applied over a considerable extent of raw surface; but in several cases where the patients have been suffering from Bright's disease, the application of the acid to a comparatively small ulcer-e.g., size of a florin-piece-bas been followed by the blackish-green discoloured urine. On the contrary, in a case of extensive scald where the whole front of the chest presented a healthy granulating surface, to which the carbolic acid was applied constantly for weeks, no discolouration or alteration of the urine whatever was produced. And in another case the discolouration of the urine was. intermittent, although the acid was kept constantly applied to the raw surface. It would seem that the urine is more easily and quickly discoloured by the ontward application of the acid, and without the occurrence of any unpleasant symptoms or inconvenience to the patient than by its internal administration. In only a few of a number of cases, where a weak solution of the acid applied externally produced a deep-olive colour of the urine, was any discolouration produced by the internal use of the acid. In two cases of chronic Bright's disease with small superficial ulcers of the legs to which the carbolic lotion was applied, the urine (in both cases) on the second day was of the dark-green colour. Carbolic acid given internally in three-grain, increased to six-grain, doses, three times daily for a week, until, toxic symptoms-as oppression of the head, epigastric pain, and vomiting-appearing, the acid had to be discontinued, produced no change in the colour of the urine of the one, but in the other the urine was of the characteristic olive-green colour. In the cases of three women poisoned at Crumpsall Workhouse, in 1871, by taking carbolic acid instead of cough mixture, I remember that the urine found in the bladder after death was of a blackish-green colour, and the blood of a majenta colour. Except in colour, the urine does not differ from ordinary urine. T'be cause of the peculiar colouration is not exactly known; it has been attributed to the action of the carbolic acid upon the colouring matter of the urine, but the colouration is not by any means constant after the free application of the acid externally or its administration internally, and no change in the urine is made by the addition of carbolic acid, unless the urine contains albumen, which the acid coagulates. How is a case like the following to be explained? After an amputation of the thigh, the stump was dressed with carbolic acid dressings. On the second day the urine was of a dark-green smoky colour, and contained a copious deposit of lithates. The discolouration remained for three days, and then suddenly vanished, reappearing the next day, and then again disappearing. Strangely, the peculiar colour reappeared and disappeared alternately for about fourteen days, when it finally disappeared, although the carbolic acid was kept applied uninterruptedly. In several cases of severe erysipelas of the head and face the application of carbolised oil has produced dark-coloured urine.

Manchester.

\section{HISTORY OF A SCROFULOUS FAMILY.} By JAMES W. ALLAN.

The following very brief jottings are the result, partly of personal observation, partly of careful inquiry. The study of this history seems interesting from a clinical point of view, as illustrating the various forms in which constitutional taint may manifest itself.

"A" and "B" -brothers.

"A" is a very delicate-looking man, about middle life, with a pinched, waxy face, and symptoms which point 